\title{
Understanding HCI Policy in Spain in the Context of Accessibility
}

Loïc Martínez Normand

Universidad Politécnica de Madrid loic@fi.upm.es
Spain pioneered policies related to disability and accessibility, especially in the physical environment. The first major piece of legislation was Act 13/1982 on the Social Integration of People with Disabilities [1]. The law was published just a few years after the reinstitution of democracy in Spain in 1977 and the approval of the Spanish Constitution in 1978. Act 13/1982 is a general law that applies accessibility to social services and education, as well as to workplace and physical accessibility. This law targeted first and foremost the social integration of people with disabilities, and it was a significant success, especially in the field of employment, as it made it mandatory for private companies and public administrations to employ a certain percentage of persons with disabilities. This greatly increased the employability of people with disabilities, as highlighted in a document celebrating 30 years of Act 13/1982 [2].

Over the past 20 years, policy makers have also focused on accessibility to information and communication technologies (ICT), developing first the national com puting accessibility standards and then specialized legislation. Initially, Spanish activities were mostly national but have now gained an international dimension.
All these initiatives are strongly related to the discipline of human computer interaction, as the key component of an accessible system is its user interface.

\section{ICT Accessibility Standards in Spain}

Spain was one of the first countries in the world to publish official standards containing accessibility requirements in computing, includ ing both hardware and software. In 1998, the Spanish national standardization body AENOR (Asociación Española de Normatización y Certificación in Spanish [3]) published two experimental national standards: UNE 139801:1998 EX [4] for hardware and UNE 139802:1998 EX [5] for software and Web (UNE stands for Una Norma Española in Spanish, that is, "a Spanish stan dard," and EX stands for experimental). These two standards were developed by National Technical Committee 139 (ICT for Healthcare) Subcommittee 8 (Systems and Devices for Older Persons and Persons with Disabilities), abbreviated as AEN CTN 139/SC 8.

Note that the standards published by AENOR are voluntary. In principle, organizations and individuals are not obliged to apply any AENOR standard, including accessibility norms. A standard becomes mandatory only if it is defined as such by law. In fact, spanish laws can make the use of AENOR stan dards mandatory. A subsequent section gives examples of laws making the use of ICT accessibility standards mandatory.

UNE 139801:1998 EX provided general accessibility requirements for the central processing unit and peripherals, and more specific requirements for displays, keyboards, mice, printers, and scanners. UNE 139802:1998 EX provided acces sibility requirements for operating systems (including general, windows, keyboard, and mouse requirements), applications (including general and windows requirements), and the Web (including browser and Web-page requirements).

This began as a national concern and has internationalized over the years. In 2001, Spanish experts participated in a Workshop on Design for All and Assistive Technologies in ICT, organized by CEN (European Committee for Standardization [6]) and related to European Mandates M/273 [7] and M/283 [8]. The workshop resulted in the publication of the CEN Workshop Agreement CWA 14661 "Guidelines to Standardisers of ICT Products and Services in the CEN ICT Domain" in 2003 [9].

CWA 14661 provided specific guidance for ICT when applying ISO/IEC Guide 71 [10], a general guideline for 
standards developers to address the needs of older persons and persons with disabilities, published jointly by the International Organization for Standardization (ISO [11]) and the International Electrotechnical Commission (IEC [12]) in 2001. This ISO/IEC guideline was published in Europe as GEN Guide 6.

CWA 14661 contained computing accessibility checklists (based on several international sources, such as ISO TS 16071 drafts [13], IBM accessibility checklists [14], and standards for Section 508 of the U.S. Rehabilitation Act [15]) that were the basis for updating the Spanish national standards. The result was the publication of UNE 139801:2003 (hardware) [16] and UNE 139802:2003 (software) [17] in 2003, and the publication of UNE 139803:2004 (Web content) [18] in 2004. This latter standard was the Spanish equivalent of the Web Content Accessibility Guidelines (WCAG) 1.0, published by the World Wide Web Consortium in 1999 [19].

UNE 139801:2003 contained hardware accessibility requirements for controls and switches, keys and keyboards, screens, audio, data-storage devices, external connections, timing and documentation, among others. UNE 139802:2003 contained gen eral software accessibility requirements and more specific requirements for keyboards, pointing devic es, screens, sounds and multimedia, user notification, object information, timing and documentation, among others. UNE 139803:2004 contained the WCAG 1.0 Web content accessibility checkpoints, organized into the following sections: general principles, presentation, structure, content, navigation, scripts, programmatic objects, multimedia, and exceptional situations.

Once these updated standards were published, AENOR started to

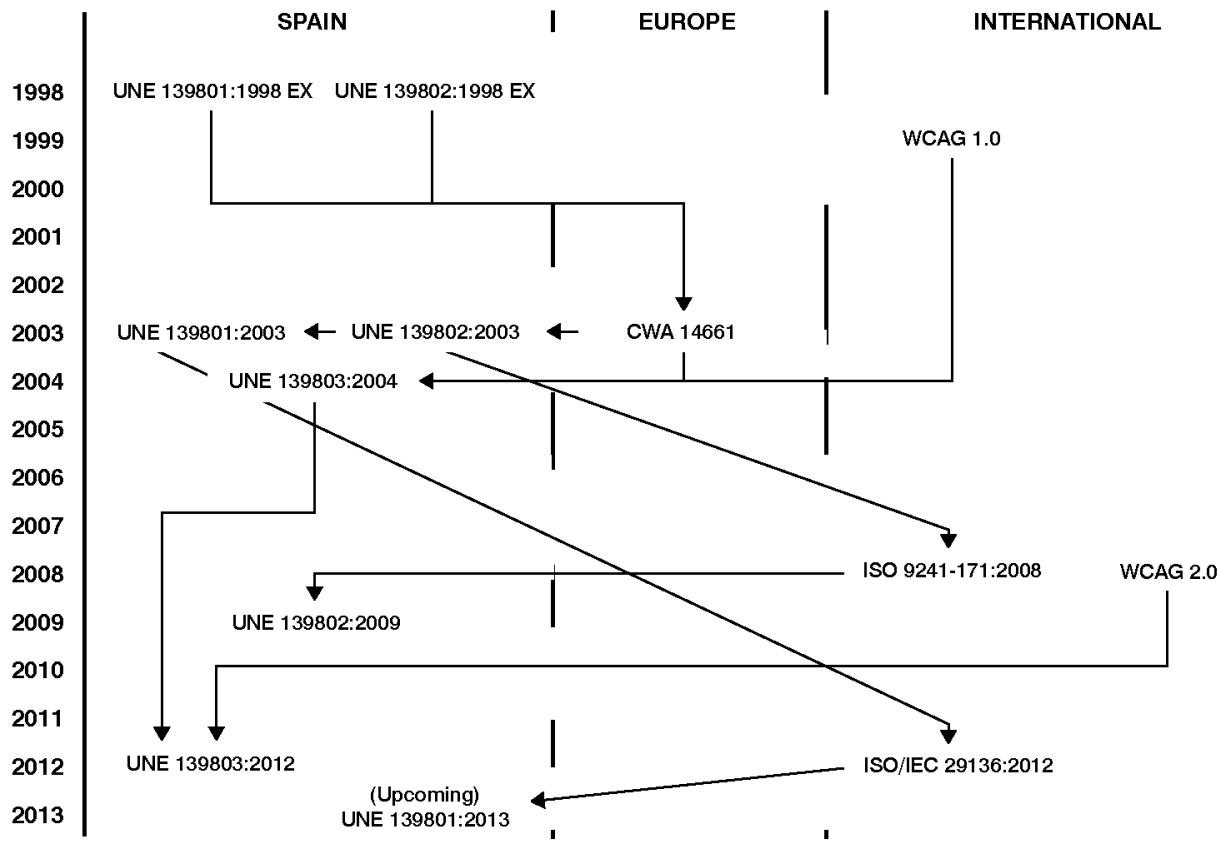

promote them internationally. This led to active Spanish participation in the development of international standard ISO 9241-171 on software accessibility (an update of ISO TS 16071), which was published in 2008 [20] and adopted and translated to Spanish as an updated UNE 139802 in 2009 [21].

ISO 9241-171:2008 (and UNE 139802:2009) contains general software accessibility requirements and recommendations (including names, labels, user preferences, accessibility adjustments, control and operation, and compatibility with assistive technology and closed systems) and specific guidelines for inputs (including alternative input functions, keyboard focus, keyboard input, and pointing devices), outputs (including visual output, text, fonts, color, window appearance and behavior, audio output, captions, media, and tactile output), and documentation and support services.

Spain pursued the same policy of active participation with respect to the recently published international standard on hardware accessibility, ISO/IEC 29136 [22], which is also expected to be translated and adopted by AENOR.
And in the Web domain, AENOR has recently adopted the 2008 WCAG 2.0 [23], unchanged. The result is an updated version of UNE 139803, which was published in July 2012 [24].

Figure 1 summarizes the timeline of these standardization activities and relationships with international efforts. Other relevant standards related to ICT accessibility published by AENOR are UNE 153010:2012 for captions [25], UNE 153020:2005 for audio description [26], and UNE 139804:2007 for the use of Spanish sign language in computer networks [27].

\section{ICT Accessibility-Related Legislation in Spain}

Public administration in Spain is roughly divided into three levels: state (the Spanish government). regional (autonomous communities), and local (city councils). The legislation described here is produced at the state level, proposed by the Spanish government (one or several ministries), approved by the national parliament, and signed by the King of Spain.

The Spanish government ministry dealing with social affairs is usually Figure 1. Timeline
of standardization
activities in Spain. 
responsible for accessibility-related issues. Note that the names and responsibilities of Spanish minis tries tend to change whenever a new government comes to power Social affairs now fall under the Ministry of Health, Social Policy and Equality [28]. Within this ministry, social services are run by the Institute of the Elderly and Social Services (IMSERSO) [29]. There are two important organizations related to IMSERSO dealing with accessibility: CEAPAT (the National Reference Centre for Personal Autonomy and Technical Aids) [30] and the Royal Board on Disability [31]. These two organizations promote accessibility activities, which sometimes result in national legislation.

The first national legislation related to ICT accessibility in Spain was published in 2002, when Act 34/2002 on Information Society Services and Electronic Commerce was passed [32]. Act 34/2002 transposed several European directives and made the accessibility of public administration websites (at the three levels: state, regional, and local) mandatory by December 2005 at the latest. Unfortunately, the law contained no specific details about Web-accessibility requirements, as the Spanish standard UNE 139803 had not yet been published.

A year later, the Spanish government published Act 51/2003 on Equality of Opportunities, Non-Discrimination and Universal Accessibility for Persons with Disabilities [33]. Act 51/2003 is an update of Act 13/1982, and it applies to the fields of telecommunications and information society; urban public spaces, infrastructure, and buildings; transport; goods and services for public use; and communication with the public administration.

Act $51 / 2003$ is a framework law that required the development of additional rules for detailed implementation. This took several years, and these additional rules were finally published in 2007:

- Royal Decree 1494/2007 [34] established the basic accessibility requirements for ICT accessibility, referencing the national standards UNE 139801, UNE 139802, and UNE 139803 for detailed requirements. Only UNE 139803 was to be mandatory for public administration websites, with conformance by December 2008 at the latest. The accessibility requirements con tained in Royal Decree 1494/2007 were the result of liaison between three ministries: the Ministry of Industry, Tourism and Commerce, the Ministry of Labour and Social Affairs, and the Ministry of Public Administrations.

- Act 49/2007 defined the breaches and sanctions related to non-compliance with Act 51/2003 [35]. This law defines three levels of breaches (minor, serious, and very serious), and penalties in the range of 300 to 30,000 euros for minor breaches, up to 90,000 euros for serious breaches, and up to 1 million euros for very serious breaches.

This was the first time there was legislation in Spain entitling people with disabilities and their representative organizations to bring accessibility cases to court, albeit only when the breaches apply across more than one region of Spain.

According to the Spanish legal system, the autonomous communities have to transpose Act 51/2003 into their legislation (in the same way that European countries have to transpose European Union law into national legislation) for regional breaches to be pursued. This process takes several years, and so far only one autonomous community (Navarre) has transposed the national legislation [36].
- Act 56/2007 [37] extended the obligation to develop accessible websites to some private organizations: companies providing economically important public services, such as telecommunications, banking, insur ance, water, gas, electricity, transport, and travel agencies. The provision of accessible websites by such companies is subject to the breaches and penalties of Act 49/2007.

CERMI (Spanish Committee of Representatives of Persons with Disabilities) [38] actually sued nine national companies in September 2010 for not having accessible Web pages [39]. This case has not come up before court, because the Spanish judicial system is very slow.

The most recent Spanish accessibility-related legislation was the adoption of the United Nations Convention on the Rights of Persons with Disabilities [40] in 2008. Spain adopted both the convention and its optional protocol. Together, they form an extensive set of responsibilities that the Spanish public administration has to implement in the coming years. One consequence of this adoption was the publication of Act 26/2011 [41] to adapt several Spanish laws to the UN Convention. It is also expected [2] that a new law will be produced to combine Acts 13/1982 (social integration of persons with disabilities), 51/2003 (equality of opportunities, non discrimination, and universal accessibility), and 49/2007 (breaches and sanctions).

\section{Spain and Mandate 376: Public Procurement of Accessible ICT}

The European undertaking related to the public procurement of accessible ICT is a major accessibilityrelated activity in which Spain is currently engaged. This is a similar initiative to the U.S. section 508 of the Rehabilitation Act 
[42]. This activity is being carried under European Mandate 376 [43], which is directed by the three European standards organizations: CEN [6], CENELEC (European Committee for Electrotechnical Standardization) [44], and ETSI (European Telecommunications Standards Institute) [45]. The mandate specifies a two-phase development process, with the ultimate aim of producing a European standard on accessibility requirements for ICT procured by public administrations. This standard will be accompanied by support documentation and a Web-based toolkit to help public procurers to enforce accessibility.

Technical work on Phase 1 started in 2007 and was finalized in 2008, with formal approval of the results by CEN, CENELEC, and ETSI in 2009 Phase 1 involved analyzing current ICT accessibility requirements and conformity assessment systems that could be applied to the public procurement of accessible ICT. Phase 1 results were published in reports by ETSI [46] and CEN/CENELEC [47]. During Phase 1, Spanish experts participated in the CEN/CENELEC working group, chaired by CEAPAT with AENOR acting as secretary.

Technical work on Phase 2 started in 2011 and is due to finalize in 2012 [48] with a draft European standard (EN=European Norm), support docu mentation, and an online toolkit. The draft EN will then be sent to CEN, CENELEC, and ETSI for formal commenting and approval in a process taking several months. Spanish experts are working in the teams developing all Phase 2 deliverables coordinated by a joint working group that is co-chaired by CEAPAT and with AENOR acting as secretary.

Mandate 376 is expected to have a big impact on the production of accessible ICT and is also expected to be harmonized with the American Section 508 pro cess [49] that is being updated within a similar time frame.

\section{The Impact of the Spanish Policy and Conclusions}

As mentioned, Spain has actively pursued the development of ICT accessibility-related policies, resulting in standards and legislation. This activity was the logical continuation of the built-environment accessibility policies that were actively promoted by organizations like ONCE (the national Spanish organi zation for the blind) and the ONCE Foundation (which provides support for other disabilities).

However, the real impact of these policies has been quite limited. As highlighted by CERMI, awareness has grown substantially, and all stakeholders are now familiar with accessibility. Even so, the number of accessible ICT products and services has not increased significantly [50]. The ONCE Foundation [51] runs a Spanish eAccessibility observatory that has analyzed the accessibility of websites by sector. For instance, it analyzed national ministry websites in 2008 [52] and public university websites in 2010 [53]. Generally, it has found that websites offer a moderate degree of support for accessibility techniques, but very few sites fully conform to the Web content accessibility guidelines.

This is not unique to Spain, but quite common across Europe, as highlighted by the Measuring Progress of eAccessibility in Europe (MeAC) study [54] and the Monitoring eAccessibility European Project [55]. In fact, the last report from the Monitoring eAccessibility Project rates Spain as having one of the highest government Webaccessibility levels in Europe. Even so, the accessibility level is moderate and needs improvement.
Recent activities, such as Mandate 376 , are expected to lead to a real advancement in ICT accessibility in the future. But it is true that our society needs a profound change of mind-set. We all need to be aware of the diversity of human beings in our lives and create a society that sees this diversity as a challenge for improving the degree of inclusion of people with disabilities.

Several lessons can be learned from the Spanish experience in accessibility policy. First, having a strong disability community leads to accessibility legislation and an increased awareness of accessibility issues, even if the results are not always fully effective. Second, legislation making accessibility mandatory is not enough, at least in countries based on Roman law. Standards defining the legal accessibility requirements and specific laws on breaches and sanctions are essential tools for achieving the goal of providing accessible products and services for people with disabilities. And third, accessibility policies should make sure all professionals are trained in why accessibility is important and in how to provide accessible solutions. This is the only way of making sure that, in the future, accessibility is implemented not just because it is mandatory, but because it is the right thing to do.

\section{ENDNOTES:}

Complete references can be found on the Web page: http://www.cettico.fi.upm.es/dpt/interactions-hci-policy 